\title{
MRI dynamics of brain and spinal cord in progressive multiple sclerosis
}

D Kidd, J W Thorpe, B E Kendall, G J Barker, D H Miller, W I McDonald, A J Thompson

\begin{abstract}
Objective-To assess the usefulness of serial cord MRI in patients with progressive multiple sclerosis.

Methods-Monthly MRI of the brain and spinal cord with and without gadolinium enhancement was carried out in 19 patients with progressive multiple sclerosis (10 primary progressive, nine secondary progressive) over the course of one year.

Results-During this period there were 132 active lesions in the brain and only six in the cord. One hundred and twelve $(85 \%)$ active brain lesions occurred in the secondary progressive group; three new cord lesions occurred in each group. In the secondary progressive group MRI activity was high in patients who had superimposed relapses, whereas in those who progressed without relapse and in the primary progressive group it was low. Cross sectional areas of the cord decreased at the $\mathrm{C5}$ level in both groups, implying progressive atrophy of fibre tracts. There was no relation between either brain or cord MRI activity and change in disability over the study period. Conclusions-Although the detection of new lesions by frequent cord imaging using current technology has little role in the monitoring of disease activity in progressive multiple sclerosis, the serial measurement of cord cross sectional area may be important. There is also evidence to suggest that the mechanism underlying irreversible disability in patients with progressive multiple sclerosis may be different in patients who continue to relapse than in those who do not.
\end{abstract}

$(\mathcal{F}$ Neurol Neurosurg Psychiatry 1996;60:15-19)

Keywords: magnetic resonance imaging; spinal cord; progressive multiple sclerosis; disability

The application of serial brain MRI in multiple sclerosis has provided profound insights into the evolution of the pathological process over time. The relation between the extent and development of abnormalities on MRI and the clinical status and course of the patients is unclear. ${ }^{1}$ As many of the clinical effects of multiple sclerosis are associated with spinal cord disease, particularly in the progressive phase, it is essential to investigate spinal cord involvement in such patients to gain a greater understanding of the nature of disability. With the advent of new imaging techniques and the multiarray receiver coil system it is now possible to more clearly define the extent of this involvement in vivo. ${ }^{2}$ A recent study of 80 patients scanned using these techniques showed that spinal cord lesions were equally prevalent in disabled and non-disabled patients, and benign and progressive subgroups alike ${ }^{3}$; this study also showed that spinal cord atrophy was common, and that there was an association between cord atrophy and disability. It is possible that the nature of the change in spinal cord lesions over time might give a better understanding of the nature of progressive disability in multiple sclerosis. Furthermore, after the recent and successful application of brain MRI to monitor therapeutic efficacy as judged by lesion activity and area, ${ }^{4}$ it is important to determine whether serial spinal cord imaging might have a useful role in this context. With these considerations in mind we have performed a serial MRI study of the brain and spinal cord in a group of patients with progressive multiple sclerosis.

\section{Methods}

Twenty patients were recruited from the population of patients with multiple sclerosis attending the outpatient department of the National Hospital for Neurology and Neurosurgery; 10 had primary progressive multiple sclerosis, defined as a clear history of progressive neurological deterioration from the onset of the disease, without relapse or remission, and 10 had secondary progressive disease, defined as clear history of progressive neurological deterioration for at least six months, following an initial relapsing/remitting course. ${ }^{5}$ All had oligoclonal bands in the CSF, and all conformed to the criteria of Poser et $\mathrm{al}^{6}$ for clinically definite multiple sclerosis. All patients gave written informed consent to participate in the study which had been approved by the ethics committee of the Institute of Neurology and the National Hospital for Neurology and Neurosurgery.

A full history was taken from each patient, which was followed by a complete neurological examination. Disability was scored with the functional score (FS) and expanded disability status scale (EDSS) ${ }^{7}$ and the motor component of the functional independence measure (FIM) ${ }^{8}$ a scale which measures ability to perform activities of daily living (score range $0-100)$. Patients were seen at monthly intervals 
for 12 months, at which times they were questioned about new or recurring symptoms, were re-examined, and the disability was scored by a single observer (DK).

MRI PROTOCOL

All scans were carried out with a Signa $1.5 \mathrm{~T}$ superconducting system (GE Medical Systems, Milwaukee) at the time of each clinical assessment.

\section{Brain MRI}

$\mathrm{T} 2$ and proton density weighted images of the brain were acquired using a fast variable echo sequence (TR $3500 \mathrm{~ms}, \mathrm{TE}_{\mathrm{ef}} 18$ and $90 \mathrm{~ms}$ with an echo train length of eight and a $192 \times$ 256 image matrix). The brain was surveyed in $344 \mathrm{~mm}$ contiguous interleaved axial slices. T1 weighted images (TR $570 \mathrm{~ms}$, TE $13 \mathrm{~ms}$ ) were acquired 5-10 minutes after injection of gadolinium-DTPA $(0 \cdot 1 \mathrm{mmol} / \mathrm{kg})$.

\section{Sagittal spinal cord $M R I$}

Two sets of $3 \mathrm{~mm}$ thick contiguous interleaved sagittal T2 weighted FSE images were obtained with a multiarray spinal coil (GE Medical Systems, Milwaukee) with a $48 \mathrm{~cm}$ field of view, which enabled the entire cord to be visualised on a single image. Sequence variables were: TR $2500 \mathrm{~ms}, \mathrm{TE}_{\mathrm{cf}} 51$ and $102 \mathrm{~ms}$, echo train length $16,512 \times 512$ image matrix, two excitations, phase encoding superior-inferior. T1 weighted sagittal images (TR $500 \mathrm{~ms}$, TE $19 \mathrm{~ms}$ ) were acquired 15-20 minutes after injection of gadolinium-DTPA.

Brain and sagittal spinal cord scans were analysed by a neuroradiologist (BK), who was blinded to clinical details. Intrinsic brain lesions were documented and a total lesion load derived after weighting lesion size according to their largest in plane diameter: $1, \leqslant 5$ $\mathrm{mm} ; 2,5$ to $10 \mathrm{~mm} ; 3 \geqslant 10 \mathrm{~mm}$; an extra point was added for lesions with a confluent appearance-that is, extensive lesions with a smooth outline which tended to be seen around the ventricles. In the spinal cord lesions were identified only if areas of high signal intensity were seen on both proton density and $\mathrm{T} 2$ weighted scans. Lesion size was scored according to its maximum length along the cord in the sagittal image: $1, \leqslant 5 \mathrm{~mm} ; 2,5$ to $10 \mathrm{~mm} ; 3, \geqslant 10 \mathrm{~mm}$. At serial assessment the appearance of new and enlarging lesions on proton density and $\mathrm{T} 2$ weighted images, and the appearance of enhancement on $T 2$ weighted images was recorded. Active lesions were defined as any new enhancing lesion or any lesion which, although not enhancing, was either new or enlarging on the proton density and $\mathrm{T} 2$ weighted images. Lesions which showed persistent enhancement were only counted once.

\section{Axial spinal cord $M R I$}

Axial $5 \mathrm{~mm}$ thick slices of the cord were acquired using a gradient echo sequence: TR $300 \mathrm{~ms}$, TE $15 \mathrm{~ms}$, flip angle $15^{\circ}$. A single slice was acquired at each of four vertebral levels- C5, T2, T7, and T11. The images were renamed and placed in a random order so that the observer (DK) was blinded both to the identity of the patient and also to the time at which the image was acquired. The cross sectional area of the cord at each level was calculated by manually tracing the circumference of the cord images with Dispimage software (Dr DL Plummer, Department of Medical Physics, University College London) on a Sun workstation. Measurements were carried out at two separate times to assess the reliability of the observer, and the mean of the two measurements taken. Change in cord area was calculated by subtracting the mean area at the beginning of the study from that at the end. Atrophy was considered to be present when the measured area was more than 2 SDs below that of the mean areas obtained for healthy controls at the appropriate level. ${ }^{3}$

STATISTICAL ANALYSIS

Group data comparisons were made using Student's $t$, Mann-Whitney, and KruskalWallis tests as appropriate, paired observations were contrasted with the Wilcoxon matched pairs signed rank test, and correlations were made by Spearman's rank correlation method.

\section{Results}

CLINICAL ACTIVITY

One patient in the secondary progressive group had to withdraw from the study after a severe relapse; frequent flexor spasms rendered her scans uninterpretable owing to motion artifacts. These were excluded from the analysis. Table 1 shows the clinical characteristics and MRI lesion loads of the 19 remaining patients. The median number of visits per patient was 12 (range 10 to 13 ).

In the primary progressive group eight patients $(80 \%)$ deteriorated neurologically on examination resulting in a change in EDSS. In the secondary progressive group seven patients $(78 \%)$ worsened on the EDSS, of whom four had had a total of seven superimposed relapses. Overall the median change in EDSS was 1.0 (SD 0.97) (range 0-3). The median change in FIM was $11 \cdot 4$ (SD 9.0) (0-27). Change in FIM correlated with change in $\operatorname{EDSS}(r=0.808, \mathrm{P}<0.002)$.

Table 1 Clinical characteristics and MRI lesion loads in the two patient groups

\begin{tabular}{|c|c|c|c|c|c|c|c|}
\hline & Age (y) & $\begin{array}{l}\text { Disease } \\
\text { duration } \\
(y)\end{array}$ & $\begin{array}{l}\text { Duration of } \\
\text { progression } \\
(y)\end{array}$ & $E D S S$ & $\begin{array}{l}\text { FIM } \\
\text { (motor) }\end{array}$ & $\begin{array}{l}\text { Brain } \\
\text { lesion } \\
\text { load }\end{array}$ & $\begin{array}{l}\text { Cord } \\
\text { lesion } \\
\text { load }\end{array}$ \\
\hline $\begin{array}{l}\text { Primary progressive } \\
(n=10) \\
\text { Secondary progressive } \\
(n=9)\end{array}$ & $\begin{array}{l}40 \cdot 1(5 \cdot 6) \\
(32-49) \\
41 \cdot 0(8 \cdot 0) \\
(29-52)\end{array}$ & $\begin{array}{l}9 \cdot 0(5 \cdot 4) \\
(3-20) \\
10 \cdot 8(6 \cdot 6) \\
(3-22)\end{array}$ & $\begin{array}{l}9 \cdot 0(5 \cdot 4) \\
(3-20) \\
6 \cdot 4(4 \cdot 7) \\
(1-17)\end{array}$ & $\begin{array}{l}4 \cdot 9(1 \cdot 5) \\
(3 \cdot 0-7 \cdot 0) \\
6 \cdot 0(0 \cdot 7) \\
(5 \cdot 0-7 \cdot 0)\end{array}$ & $\begin{array}{l}80 \cdot 8(12 \cdot 4) \\
(63-100) \\
73 \cdot 8(14 \cdot 9) \\
(42-100)\end{array}$ & $\begin{array}{l}37 \cdot 3(50 \cdot 2) \\
(0-172) \\
79 \cdot 0(48 \cdot 8) \\
(25-164)\end{array}$ & $\begin{array}{l}6 \cdot 9(3 \cdot 3) \\
(2-11) \\
5 \cdot 2(3 \cdot 5) \\
(2-12)\end{array}$ \\
\hline
\end{tabular}

Values are mean $(\mathrm{SD})$ with range below. 
Table 2 Change in clinical and MRI activity

\begin{tabular}{|c|c|c|c|c|c|c|}
\hline & $\begin{array}{l}\text { No } \\
\text { of } \\
\text { relapses }\end{array}$ & $\begin{array}{l}\text { Clinical } \\
\text { progression: } \\
\text { no of patients }\end{array}$ & EDSS & $\begin{array}{l}\text { Brain } \\
\text { activity }\end{array}$ & $\begin{array}{l}\text { Cord } \\
\text { activity }\end{array}$ & $\begin{array}{l}\text { Total } \\
\text { CNS } \\
\text { activity }\end{array}$ \\
\hline Primary progressive & & 10 & $\begin{array}{l}1 \cdot 25(1 \cdot 0) \\
(0-3 \cdot 0)\end{array}$ & $\begin{array}{l}2.0(5.6) \\
(0-18)\end{array}$ & $\begin{array}{l}0.20(0.4) \\
(0-1)\end{array}$ & $\begin{array}{l}2 \cdot 20(5 \cdot 9) \\
(0-19)\end{array}$ \\
\hline Secondary progressive & 7 & 9 & $\begin{array}{l}0.95(0.9) \\
(0-2 \cdot 5)\end{array}$ & $\begin{array}{l}12 \cdot 4(21 \cdot 1) \\
(0-63)\end{array}$ & $\begin{array}{l}0 \cdot 33(0 \cdot 7) \\
(0-2)\end{array}$ & $\begin{array}{l}12 \cdot 78(21 \cdot 3) \\
(0-64)\end{array}$ \\
\hline With relapse & 7 & 4 & $\begin{array}{l}1.1(0.75) \\
(0.5-2.0)\end{array}$ & $\begin{array}{l}19 \cdot 0(27 \cdot 0) \\
(4-63)\end{array}$ & 1 lesion & $\begin{array}{l}19 \cdot 0(27 \cdot 5) \\
(4-64)\end{array}$ \\
\hline Without relapse & & 5 & $\begin{array}{l}0 \cdot 8(1.0) \\
(0-2 \cdot 5)\end{array}$ & $\begin{array}{l}2 \cdot 0(1 \cdot 3) \\
(0-3)\end{array}$ & 2 lesions & $\begin{array}{l}2 \cdot 0(1 \cdot 8) \\
(0-4)\end{array}$ \\
\hline
\end{tabular}

Values are median (SD) with range below unless otherwise stated.

\section{MRI ACTIVITY}

Over the study period a total of 231 scans of the brain and cord were carried out. There was a total of 132 active brain lesions, 112 $(85 \%)$ of which occurred in the secondary progressive patient group; 107 (95\%) of these enhanced. There were 20 active brain lesions in three primary progressive patients, of which $14(70 \%)$ enhanced (13 in one patient). The median number of active brain lesions was significantly greater in the secondary progressive group $(P=0.02)$ (table 2). Median brain lesion activity was $19 \cdot 0$ (SD 27.0) (4-63) in the four secondary progressive patients who had had superimposed relapses, 2.0 (SD 1.3) $(0-3)$ in the five who had progressed without relapse $(P<0.02)$ and 2.2 (SD 5.6) $(0-18)$ in the 10 primary progressive patients (table 2 ).

There was a total of six active lesions in the spinal cord (four new and two enlarging), of which only one was seen to enhance (in a secondary progressive patient); three of the lesions were in the primary progressive group, three in the secondary progressive group. All six patients with cord activity showed new activity on brain MRI.

The median combined number of active brain and cord lesions was greater in the secondary progressive than the primary progressive group $(P=0.02)$. In the secondary progressive group MRI activity was significantly greater in those who had had superimposed relapses compared with those without $(\mathrm{P}<0.05)$.

\section{CROSS SECTIONAL AREAS OF THE CORD \\ (TABLE 3)}

Intrarater reliability was $2 \cdot 0 \%$. There was a reduction in cord area which was most pronounced at the $\mathrm{C} 5$ level (median change in area $=-2.62 \mathrm{~mm}^{2}$, range -20.45 to +6.70 $\left.\mathrm{mm}^{2}\right)(\mathrm{P}<0.05$; figure $)$, and was greater in the primary progressive group (median change $-5.39 \mathrm{~mm}^{2}$, range -20.45 to $+5.15 \mathrm{~mm}^{2}$ ) than the secondary progressive group (median change $-2.62 \mathrm{~mm}^{2}$, range $-17 \cdot 10$ to $+6 \cdot 70$ $\mathrm{mm}^{2} ; \mathrm{P}<0.05$ for both groups). The reduction in cord area was significant at $\mathrm{C} 5$ both for the entire group and the individual subgroups $(\mathrm{P}<0.05)$.

\section{RELATION BETWEEN MRI FINDINGS AND} CLINICAL CHANGE

Eight patients (six primary progressive, two secondary progressive), four of whom had deteriorated on the EDSS, had no active MRI lesions. There was no significant correlation between brain or total CNS activity and change in EDSS or FIM in the 19 patients as a whole, nor in the two subgroups, although total CNS activity did correlate with change in both EDSS and FIM $(r=0.83, \mathrm{P}<0.05)$ in the four secondary progressive patients who relapsed.

There was no significant difference in MRI brain activity in those who changed by $\geqslant 1.0$ on the EDSS compared with those who changed less (median activity 2.0 (SD 10.3) $(0-30) v 0.0(\mathrm{SD} 19 \cdot 8)(0-63))(\mathrm{P}=0.3)$.

There was no correlation between change in cord area at any of the four levels and change in EDSS or FIM, nor between MRI activity in the brain or cord; there was, however, a trend towards a significant difference between change in cord area in those who changed $<1.0$ on EDSS and those whose change was greater, this trend was most noticeable at C5 (median change in area $-1 \cdot 7(-8 \cdot 2$ to $+5 \cdot 9$ $\left.\mathrm{mm}^{2}\right) v-5 \cdot 2\left(-20 \cdot 45\right.$ to $\left.+5 \cdot 15 \mathrm{~mm}^{2}\right), \mathrm{P}=$ $0 \cdot 8)$. There was no significant difference between change in cord area of patients who had had active lesions (median -3.68 (range $-7 \cdot 1$ to $+6 \cdot 70 \mathrm{~mm}^{2}$ )) and those who had not (median -1.25 (range -20.45 to $+5 \cdot 15$ $\left.\left.\mathrm{mm}^{2}\right)\right)(\mathrm{P}>0.5)$.

\section{Discussion}

The use of multiarray coils with fast spin echo has greatly increased the resolution of spinal cord imaging. In the present study patients with progressive multiple sclerosis had much

Table 3 Cross sectional cord areas at onset and end of study

\begin{tabular}{|c|c|c|c|c|c|c|c|c|}
\hline & \multicolumn{4}{|c|}{ Cross sectional areas at onset of study $\left(\mathrm{mm}^{2}\right)$} & \multicolumn{4}{|c|}{ Cross sectional areas at end of study $\left(\mathrm{mm}^{2}\right)$} \\
\hline & $C 5$ & $T 2$ & $T 7$ & $T 11$ & $\overline{C 5}$ & $T 2$ & $T 7$ & $T 11$ \\
\hline $\begin{array}{l}\text { Total patient } \\
\text { population } \\
\text { Primary } \\
\text { progressive } \\
\text { Secondary } \\
\text { progressive }\end{array}$ & $\begin{array}{c}100 \cdot 70(10 \cdot 82) \\
(73 \cdot 85-114 \cdot 5) \\
101 \cdot 47(9 \cdot 96) \\
(84 \cdot 2-111 \cdot 1) \\
98 \cdot 25(12 \cdot 32) \\
(73 \cdot 85-114.5)\end{array}$ & $\begin{array}{l}60 \cdot 10(7 \cdot 44) \\
(43 \cdot 35-70 \cdot 20) \\
58 \cdot 30(6 \cdot 99) \\
(47 \cdot 90-71 \cdot 75) \\
61 \cdot 03(9 \cdot 86) \\
(39 \cdot 60-72 \cdot 35)\end{array}$ & $\begin{array}{l}50 \cdot 35(6 \cdot 36) \\
(34.80-60 \cdot 10) \\
50 \cdot 20(6 \cdot 71) \\
(34.8-58 \cdot 0) \\
51 \cdot 25(6 \cdot 35) \\
(39.05-60 \cdot 10)\end{array}$ & $\begin{array}{l}64 \cdot 20(8 \cdot 18) \\
(39 \cdot 70-77 \cdot 20) \\
63 \cdot 15(6 \cdot 56) \\
(53 \cdot 20-77 \cdot 20) \\
64 \cdot 82(9 \cdot 81) \\
(39 \cdot 70-71 \cdot 70)\end{array}$ & $\begin{array}{l}96 \cdot 73(11 \cdot 10) \\
(70 \cdot 8-109 \cdot 25) \\
96 \cdot 73(10 \cdot 87) \\
(70 \cdot 8-105 \cdot 3) \\
96 \cdot 57(12 \cdot 00) \\
(71 \cdot 1-109 \cdot 25)\end{array}$ & $\begin{array}{l}59 \cdot 56(8 \cdot 14) \\
(39 \cdot 60-72 \cdot 35) \\
57 \cdot 70(7 \cdot 04) \\
(46 \cdot 1-67 \cdot 75) \\
60 \cdot 40(8 \cdot 12) \\
(43 \cdot 35-70 \cdot 20)\end{array}$ & $\begin{array}{l}51 \cdot 98(8 \cdot 42) \\
(34 \cdot 15-66 \cdot 20) \\
49 \cdot 90(8 \cdot 53) \\
(34 \cdot 15-61 \cdot 35) \\
52 \cdot 20(8 \cdot 84) \\
(37 \cdot 25-66 \cdot 20)\end{array}$ & $\begin{array}{l}65 \cdot 76(8 \cdot 16) \\
(56 \cdot 20-80 \cdot 0) \\
67 \cdot 45(8 \cdot 95) \\
(56 \cdot 20-80 \cdot 0) \\
62 \cdot 30(6 \cdot 00) \\
(56 \cdot 75-71 \cdot 40)\end{array}$ \\
\hline
\end{tabular}

Values are median (SD) with range below. 
Axial slice of cord (gradient echo) of patient with primary progressive multiple sclerosis at the beginning $(A)$ and end (B) of 12 month study period showing a reduction in cross sectional area from $88 \mathrm{~mm}^{2}$ to $83 \mathrm{~mm}^{2}$. The patient deteriorated clinically with EDSS going from 3.5 to 5.5 and had no new lesions of brain or cord during the study.

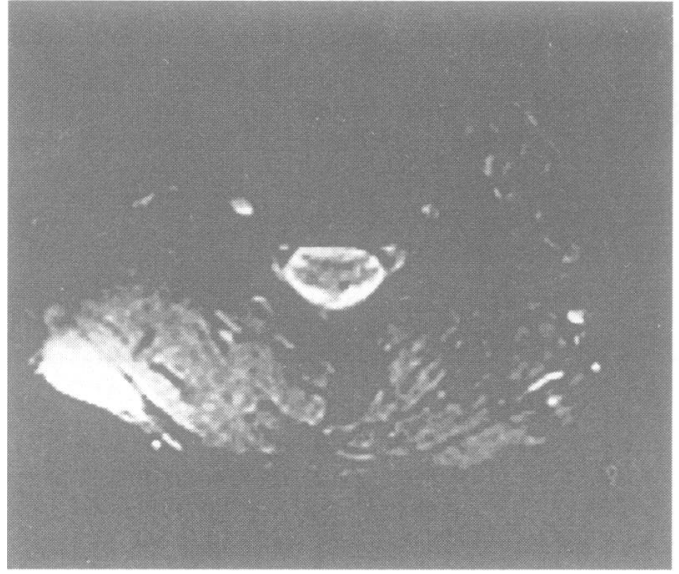

A

less detectable activity in the spinal cord than in the brain. Only six active cord lesions were seen over a 12 month period compared with 132 active lesions in the brain. No patient had cord activity in the absence of brain activity. A failure to detect more cord activity in a patient population which showed quite pronounced clinical change over the study period is perhaps surprising. This may in part relate to our inability to detect small lesions within the cord which, although capable of producing detectable clinical deficit, may be beyond the resolution of existing techniques. The location of the lesion within the cord may also be important and this would be better appreciated on systematic axial imaging of the whole cord which was not performed in this study. Nevertheless, these results suggest that in its present state serial imaging of the cord to detect new disease activity would not make useful a contribution in therapeutic trials of progressive multiple sclerosis.

Another aspect of spinal cord pathology which may be important to monitor is that of atrophy. It has recently been shown that patients with multiple sclerosis have on average a smaller cord area that normal controls. ${ }^{3}$ In the same study patients who had cord atrophy (defined as an area more than 2 SDs below the mean for normal controls) were more disabled than those who did not have atrophy. In the present study atrophy was measured serially by a single blinded observer. There was good intrarater reliability of the measurement technique used (2\%), and a reduction in cord area was seen in 15 patients over a 12 month period. This was most pronounced at the C5 level, which has a higher proportion of pyramidal tract fibres that at any other level of the cord. There was also a nonsignificant trend suggesting that patients with progressive atrophy were more likely to develop increasing disability. It seems likely that axonal loss makes an important contribution to such progressive atrophy thus giving further evidence that this pathological process plays a significant part in the development of progressive functional deterioration. Further data are required to determine the usefulness of measuring cord atrophy in therapeutic trials. A larger number of patients will need to be

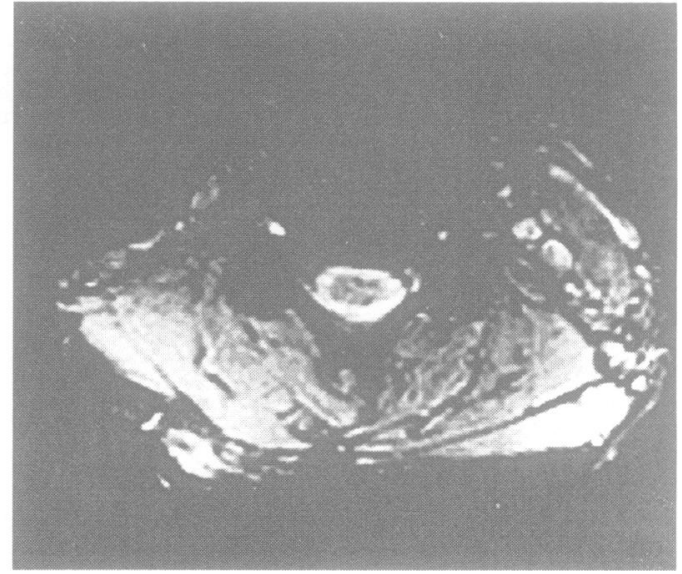

B

studied over a longer period of time.

The results of this study raise interesting questions with regard to the development of disability in multiple sclerosis. One of the main findings is that a number of patients developed disability in the absence of any obvious new MRI activity. There is already evidence to suggest that patients with primary progressive multiple sclerosis have a different pattern of MRI activity than those in the relapsing and remitting and secondary progressive groups. ${ }^{9}$ Patients in this group tend to have fewer lesions on brain MR and develop fewer new or enhancing lesions over time. The hypothesis that this may be a less inflammatory form of multiple sclerosis is supported by a recent pathological study. ${ }^{10}$ The mechanism by which such patients develop disability is not clear but again may be explained by progressive axonal loss in pre-existing lesions rather than obvious new demyelinating lesions. In the present study five of the nine patients with secondary progressive multiple sclerosis deteriorated without any superimposed relapses and these patients also showed few, if any, new lesions in the brain or spinal cord, their MRI activity being very similar to that of the patients in the primary progressive group. Similar findings have been made by our group in a larger serial study of the brain which did not involve the use of gadolinium DTPA. ${ }^{11}$

These findings may have important implications both for our understanding of the nature of disability and for the role of MRI in monitoring that activity. They suggest that there may be more than one mechanism for the development of disability. On the one hand, in relapsing and remitting patients and in secondary progressive patients who continue to relapse, disability may relate directly to the formation of new lesions. On the other hand there is a group of patients in whom development of progressive disability may relate to mechanisms not as clearly demonstrated through conventional MRI, including progressive axonal loss. This emphasises the importance of the development of new MR techniques which will allow clearer identification of axonal loss. ${ }^{12}$

In summary this study shows that whereas at present the detection of new lesions in the 
spinal cord does not make a useful contribution to monitoring of disease activity in progressive multiple sclerosis the measurement of cord atrophy may be important. There may be different mechanisms in the development of disability and the results emphasise the need to develop MR techniques which will allow them to be measured (particularly axonal loss). This will allow a better understanding of the nature of disability and result in more accurate monitoring of disease activity in therapeutic trials. ${ }^{12}$

The NMR Research Group is funded by a generous donation from the Multiple Sclerosis Society of Great Britain and Northern Ireland. DK was funded by the Brain Research Northern Ireland. DK was funded by the Brain Research
Trust. The support of Mr David MacManus and Ms Stephanie Trust. The support of Mr David MacManus and Ms Stephanie
Webb is gratefully acknowledged. The multiarray coil and fast Webb is gratefully acknowledged. The multiarray coil and fast
spin echo sequences were provided by GE Medical Systems, spin echo sequen

1 McDonald WI, Miller DH, Barnes D. The pathological evolution of multiple sclerosis. Neuropathol Appl Neurobiol 1992;18:319-34.

2 Thorpe JW, Kidd D, Kendall BE et al. Spinal cord MRI using multi-array coils and fast spin echo: 1 . technical aspects and findings in healthy adults. Neurology 1993; 43:2625-31.
3 Kidd D, Thorpe JW, Thompson AJ, et al. Spinal cord MRI using multi-array coils and fast spin echo: 2 . findings in using multi-array coils and fast spin echo: 2 .

4 Paty DW, Li DKB, and the UBC/MRI study group. Interferon beta-1b is effective in relapsing-remitting multiple sclerosis. II: MRI analysis results of a multi-centre, randomised, double-blind, placebo-controlled trial. Neurology 1993;43:662-7.

5 Matthews WB. Course and prognosis. In: Matthews WB Martyn CN, Allen IV, Compston DAS, eds. McAlpine's multiple sclerosis. London: Churchill Livingstone, 1992: 142-55.

6 Poser CM, Paty DW, Scheinberg L, et al. New diagnostic criteria for multiple sclerosis: guidelines for research protocols. Ann Neurol 1983;13:227-31.

7 Kurtzke JF. Rating neurologic impairment in multiple sclerosis: an expanded disability status scale (EDSS) rosis: an expanded disability

8 Granger CV, Hamilton BB, Keith RA, et al. Advances in functional assessment for medical rehabilitation. Topics in Geriatric Rehabilitation 1986;1:59-74.

9 Thompson AJ, Kermode AG, Wicks D, et al. Major differences in the dynamics of primary and secondary progressive multiple sclerosis. Ann Neurol 1991;29:53-62.

10 Revesz T, Kidd D, Thompson AJ, Barnard RO, McDonald WI. A comparison of the pathology of primary and secondary progressive multiple sclerosis. Brain 1994, 117:759-65.

11 Kidd D, Thompson AJ, Miller DH, Kermode AG, McDonald WI. MRI activity and disability in MS: a two year study [abstract]. I Neurol Neurosurg Psychiatry year study $1992 ; 55: 1213$

12 McDonald WI, Miller DH, Thompson AJ. Are magnetic resonance findings predictive of clinical outcome in therapeutic trials in multiple sclerosis? The dilemma of interferon- $\beta$. Ann Neurol 1994;36:14-8. 